\title{
Competition among Telecommunication Providers
}

\author{
Patrick Maillé $^{1}$, Peter Reichl ${ }^{2}$, and Bruno Tuffin ${ }^{3}$ \\ ${ }^{1}$ Télécom Bretagne, Cesson-Sévigné Cedex, France \\ ${ }^{2}$ FTW Telecommunications Research Center Vienna, Austria \\ ${ }^{3}$ INRIA Rennes Bretagne-Atlantique, Campus de Beaulieu, France \\ patrick.mailleatelecom-bretagne.eu, reichl@ftw.at, \\ bruno.tuffin@inria.fr
}

\begin{abstract}
We analyze in this section game-theoretic models of competition between telecommunication networks providers in various contexts. This analysis helps to define and understand the operators' pricing and technology investments as well as the most efficient market rules by a regulator.
\end{abstract}

Keywords: Competition, game theory, pricing.

\section{Context}

The Internet has moved from an academic network to a commercial and highly competitive one where providers compete for customers by playing with the price to access service and the Quality of Service (QoS) they offer. There are now different ways to access the network through different technologies, using ADSL, telephone network, optic fiber, CDMA wireless networks, WiFi or WiMAX among others, with different QoS capabilities. Moreover, the convergence of networks, where Internet access, wired and wireless telephony, television are regrouped into a single network poses additional economic challenges. In this situation, each provider has to adapt his pricing scheme in order to attract customers, to maximize his revenue and/or to allow fairness in the way resources are shared. Pricing has therefore been a hot topic in telecommunication networks during the last decade (due to congestion) and many schemes have been proposed in the literature [1,2,15].

On the other hand competition among providers has received very little attention up to now. Though, telecommunication networks have become highly competitive and it seems primordial to us to deal with that competition in pricing models when defining the optimal prices, since competition may highly affect the results of price determination (while pricing in a monopolistic context generally means a single level of game between users, competition actually introduces an additional level of game, between providers). Some typical illustrations of competition are described below.

For wired access, DSL users can choose among several competing providers to connect to the Internet.

1. The case of wireless access is more flexible. For example a user wishing to connect to a WiFi hotspot may be located in a zone covered by several wireless access providers, and can choose which provider to use for the time of his connection. 
The same user can/will even be able to choose between different and competitive transmission platforms: WiFi, WiMAX, 3G, wired operators, FTTx (Fiber To The X), with a possible combination of all those ones (the so-called multi-homing). Depending on the context, providers are or can be forced to share a part of the available resource.

Our goal in this section is to deal with that issue. Indeed, we need to study the distribution of customers among providers as a first level of game, and then to focus on a second higher level, the price and QoS war among providers. We aim at summarizing some of the main findings of the French ANR project CAPTURES (see http://captures.inria.fr/), run in conjunction with Econ@Tel, whose main goals are:

- To provide models and analysis of direct competition among providers operating on the same or different technologies (being WiFi, WiMAX, 3G, ADSL...) and the dynamics of those models.

- To discuss capacity expansion for providers from an economic point of view.

- To analyze retention policies that prevent users from churning, and how this can be controlled.

- In general, to discuss regulation rules that could help to drive the system to an optimal situation.

The key tools are telecommunication networks modeling, non-cooperative game theory and optimization.

Figure 1 illustrates the type of situation to be analyzed with different providers (DSL, wireless, etc.) not necessarily covering all users. Those providers have to define their price ( $p_{i}$ for provider $i$ ) at the largest time scale as a game (they can additionally play with capacity, QoS and other parameters). At the smallest time sale, depending on the offered QoS and the price at each provider, demand is split among providers. Those two games are strongly dependent: the way demand is distributed depends on prices set by all providers; similarly the price strategy of a provider will depend on demand distribution. What complicates more, even at the first step, demand depends on QoS, itself depending on the number of attracted customers. But we assume that providers play smartly by anticipating the reaction of users to the price profile (the so-called backward induction).

This type of two levels game is called a Stackelberg game [14], where providers are leaders playing first and anticipating the reactions of users.

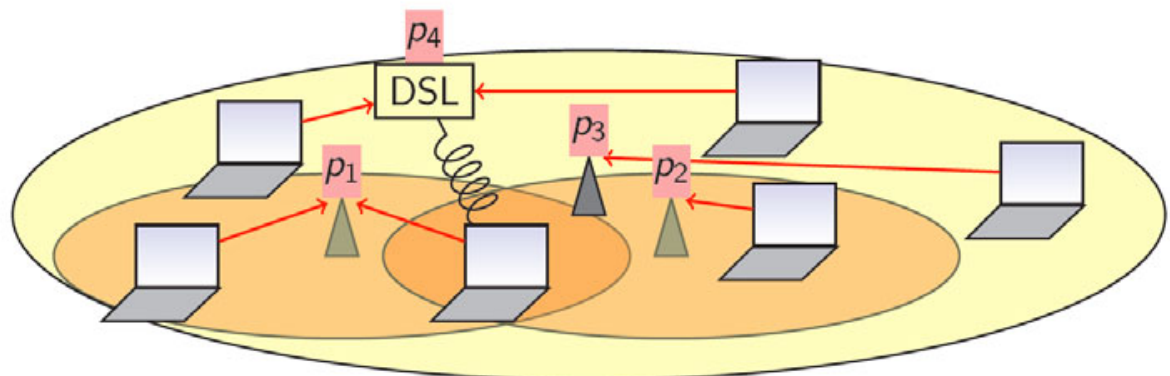

Fig. 1. Typical two-levels model 


\section{Demand Distribution among Providers and Influence on Price War}

To model the competition among providers, we use the above two-levels Stackelberg game. The questions are: How to characterize the equilibrium in the distribution of customers among providers? Does it exist and is it unique? Is there a Nash equilibrium in the price war between providers? Recall that a Nash equilibrium is a vector of providers' strategies such that no provider can improve his revenue by unilaterally changing his own strategy. If it exists, is this equilibrium unique and what can drive the system to a "good" one?

There are several ways to represent the demand of end users, such as attraction models, coming from marketing theory (a well-known class being the generalized MultiNomial Logit (MNL) [3]. But for illustration purposes here, we consider a demand repartition coming from transport theory. In that case, each packet is like a car on a road, and its influence on the resulting traffic can be seen as negligible. Then demand will be split in such a way that for each route (at each provider), the perceived cost, made of the charge imposed on customers and the level of QoS provided, will be equal for each provider receiving some traffic. Indeed, otherwise part of the traffic at an "expensive" provider could be re-routed to a "cheaper" provider. The resulting equilibrium is called a Wardrop equilibrium [16].

We start with the model and results described in [10], where $N$ providers compete on the exact same domain, as depicted in Figure 2. Time is slotted and Provider $i$ is able to serve $C_{i}$ packets (or units) per slot. If his demand is $d_{i}$, packets in excess (chosen uniformly) are lost and have to be resent. Figure 3 describes this loss model, the (uniform) probability of transmission success and the expected number trials before success (from a geometric distribution). Following [13], we assume that the price $p_{i}$ at provider $i$ is per sent packet and not received ones, a congestion pricing to incentivize users to efficiently use the capacity. The perceived price per received packet is then $P_{i}=p_{i} \max \left(1, d_{i} / C_{i}\right)$.

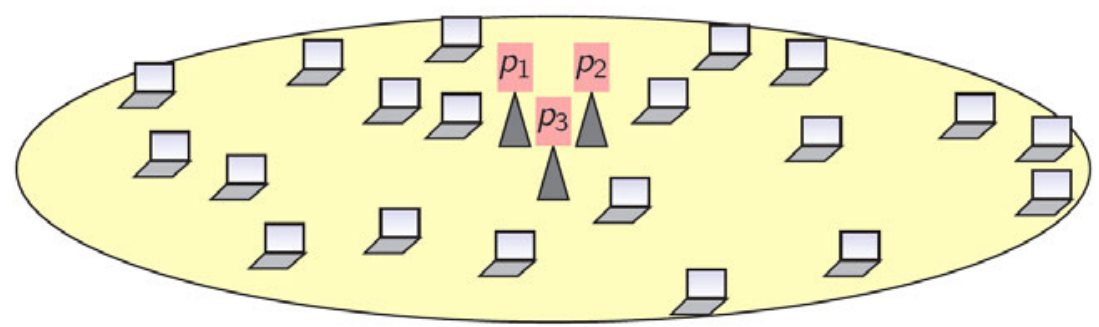

Fig. 2. Example with 3 providers covering the same domain 


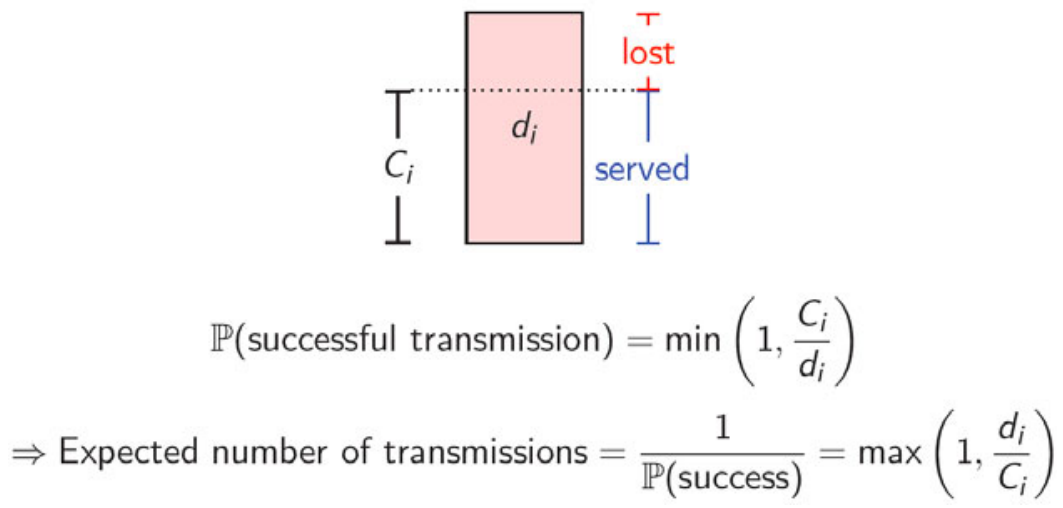

Fig. 3. Description of the loss and retransmission model

Users try to choose the providers with the cheapest perceived price. According to Wardrop's principle, all providers with positive demand have the same perceived price $P=P_{i}$, otherwise some users would have an interest to switch, and operators with a price $P_{i}$ larger than $P$ have no demand (they are too expensive). We assume that there is a total demand function $D$ that depends on the perceived price $P$, and which is continuous, strictly decreasing on its support. Total demand is also equal to the total sum of received packets. It can be shown (see [10]) that there exists an equilibrium demand $d=\left(d_{i}\right)_{i}$ and that the perceived price is unique at that equilibrium.

Using this equilibrium on the demand distribution, providers play (by anticipation) their pricing game, trying to maximize their revenue $R_{i}$, knowing that increasing their price could incentivize users to move to competitors. The revenue $R_{i}$ is the product of demand $d_{i}$ and price $p_{i}$. Under assumptions on the elasticity of demand (of absolute value larger that 1), or if there are management costs that depend on the managed demand at each operator, we have been able to prove that there is a unique Nash equilibrium to the price war, described by the equations below. In other words, at equilibrium, all providers play the same price, and that price is such that demand equals capacity.

$$
\forall i, \quad\left\{\begin{array}{l}
p_{i}=D^{-1}\left(\sum_{j} C_{j}\right) \\
d_{i}=C_{i} .
\end{array}\right.
$$

\section{Capacity/Technology Planning and Pricing in a Competitive Environment}

Pricing is an issue for providers, but capacity planning is another, at a higher level: is it worth investing in capacity in a competitive network? This is even more true if congestion pricing is applied, i.e., if customers pay more when there is congestion; in that case it might be worthwhile to voluntarily have a congested network. 
In [10], we have shown that under an assumption of sufficiently high demand elasticity, there is no interest for providers to lie on their capacity by declaring less than they actually have: they get higher revenues if using all their resource.

In $[11,12]$ we have even played an additional game at a higher level, on top of the two-levels game we have just described. The idea is to look at the investment strategies of providers, in terms of acquiring new infrastructures and licenses, in new technologies for instance (WiMAX, new 3G license, etc.), and to maintain or expand the ones they might already own (WiFi, 3G...). Providers are usually heterogeneous because they already own different infrastructures and licenses and have different costs. We have thus defined a so-called third level technological game where each provider $i$ chooses the subset $S_{i}$ of implemented technologies (in a set defined as $\left\{\mathrm{WiFi}\right.$, WiMAX, 3G\}), resulting in a (multidimensional) matrix of revenues $\left(R_{l}(S)\right.$, $R_{2}(S)$ ) from the above game, for all combinations of $\left(S_{1}, S_{2}\right)$, with $S=\left(S_{i}\right)_{i}$. We define similarly a cost matrix $\left(C_{l}(S), C_{2}(S)\right)$ also for all combinations of $\left(S_{1}, S_{2}\right)$ providing the cost for implementing the considered subsets of technologies. The goal of each provider $i$ is to maximize his net benefit $B_{i}(S)=R_{i}(S)-C_{i}(S)$.

Several scenarios are presented to illustrate the best investment strategies of providers in games representing for instance an already positioned $3 \mathrm{G}$ against a rather WiFi-positioned one, and their relative strategies with respect to WiMAX/LTE. Another issue is at which maximal $3 \mathrm{G}$ license price a new entrant would be willing to implement this technology and develop the corresponding architecture. (Note that in $[11,12]$ we have not used the perceived price we have described in Section 5.3.2 but a model without loss but delay at a queue and a perceived price sum of the price paid and a perceived delay cost. Though, this difference does not change the analysis in itself.

\section{$4 \quad$ Analysis of the Price of Anarchy}

It is well known from Game Theory that the conjunction of selfish decisions will not necessarily be globally optimal, and indeed can be worse for every participant of the game than some other possible outcome. However, by nature networks involve a very large number of actors of several kinds (consumers, providers, brokers), with diverging interests, so it is unreasonable to suggest that the network be centrally controlled to improve its efficiency. Therefore, the loss of efficiency due to selfish behaviors of actors cannot be ignored. This loss can be quantified by the so-called Price of Anarchy, recently defined [4] as the worst-case ratio comparing the global efficiency measure (that has to be chosen) at an outcome of the non-cooperative game played among actors, to the optimal value of that efficiency measure. If the price of anarchy is not too large, then this suggests that the system is run close to the optimum without the need for any coordination. Otherwise, some tools should be used to limit the efficiency loss (via the introduction of incentives in the network).

Remarkably, for the model presented in Section 2 (and most of the models presented in the next part), see [10], the price of Anarchy is 1 when trying to 
maximize the sum of utilities of all actors in the game, meaning that there is no loss of efficiency due to competition with respect to the case where all providers cooperate.

\section{$5 \quad$ Analysis of Specific Other Competition Contexts}

Considering the model described in Sections 2 and 3 again, but with a provider covering a smaller part of the population. It can model for instance a WiMAX (or LTE) operator against a WiFi operator as described in Figure 4. A proportion $\alpha$ of the population (i.e., of the demand function) is in the domain covered by the WiFi (thus by both operators) while a proportion 1- $\alpha$ is only covered by the WiMAX operator.

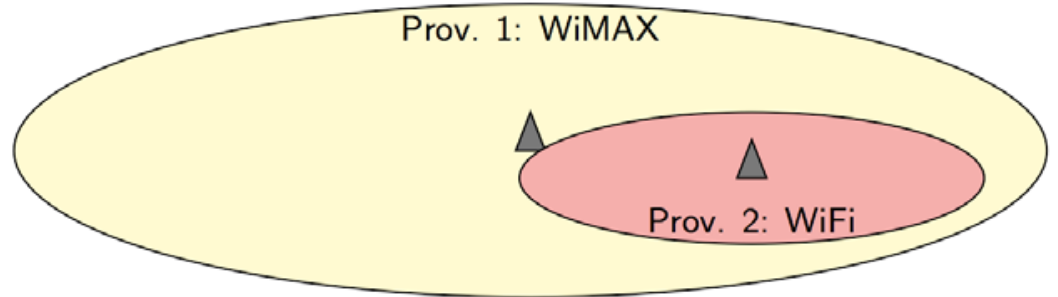

Fig. 4. Game between providers, one covering a smaller part of the population

Here again, the game is played as a two-levels game where the providers play on prices first, trying to maximize their revenue and anticipating the result of the game between users who distribute themselves between users trying to choose the provider with the cheapest perceived price, if not too expensive for them. Here also, it can be shown (see [8] for all details) that for all price profile, there exists at least a user (Wardrop) equilibrium. Moreover, the corresponding perceived prices of each provider are unique. At the level of price war between providers, using the user equilibrium to describe demand distribution, it is shown under conditions on demand elasticity similar to the previous subsection that there exists a unique Nash equilibrium $\left(p_{1}{ }^{*}, p_{2}{ }^{*}\right)$ on prices:

- If the proportion $\alpha$ of population that the $\mathrm{WiFi}$ provider can reach is smaller than the proportion of capacity owned by this WiFi provider $C_{2} /\left(C_{1}+C_{2}\right)$, then the common area is (entirely) left to the WiFi provider by the WiMAX one, which set a higher price and focus on the zone where he is in a monopoly. The equilibrium prices are

$$
p_{1}^{*}=D^{-1}\left(\frac{C_{1}}{1-\alpha}\right) \geq p_{2}^{*}=D^{-1}\left(\frac{C_{2}}{\alpha}\right) .
$$

- If on the other hand the proportion $\alpha$ of population in the common zone is larger than the proportion of capacity owned by the WiFi provider, at equilibrium there is a price war between providers, which set the same price, and share the common area. This common price is given by

$$
p_{1}^{*}=p_{2}^{*}=p^{*}=D^{-1}\left(C_{1}+C_{2}\right) .
$$


Another extension, detailed in [7], studies the situation when each provider $i$ has the capacity to serve $C_{i}$ packets (or units) per slot, but when there is a capacity $C$ that can be freely used by all providers. This basically helps to model the case when providers have their own licensed spectrum, but can use a free spectrum (for example WiFi) to send data when they are congested. Considering only two providers, the idea is that each of them uses his own capacity but sends demand in excess on the shared capacity $C$. If this capacity is overused then, there again, lost packets are chosen uniformly (which means for each provider proportionally to the amount he has sent to his shared spectrum). This is summarized in Figure 5, showing how the shared capacity is split between the two providers.

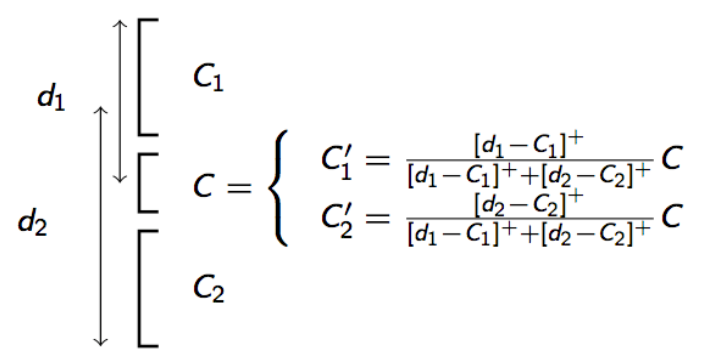

Fig. 5. Network usage with two providers when there is a shared capacity

Here again, the existence of a user equilibrium is proved, and the pricing game between providers can be studied. An interesting question to answer becomes: is it of interest to license spectrum or not? To see this, we can plot in Figure 6, for some numerical values, the utilities of all actors (aggregated users, also called user welfare (UW), revenues of the two providers, and social welfare (SW), made of utilities of users plus revenues of providers) at equilibrium in terms of the proportion $\mu=C / C_{t o t}$ of shared capacity, with $C_{t o t}=C+C_{1}+C_{2}$.

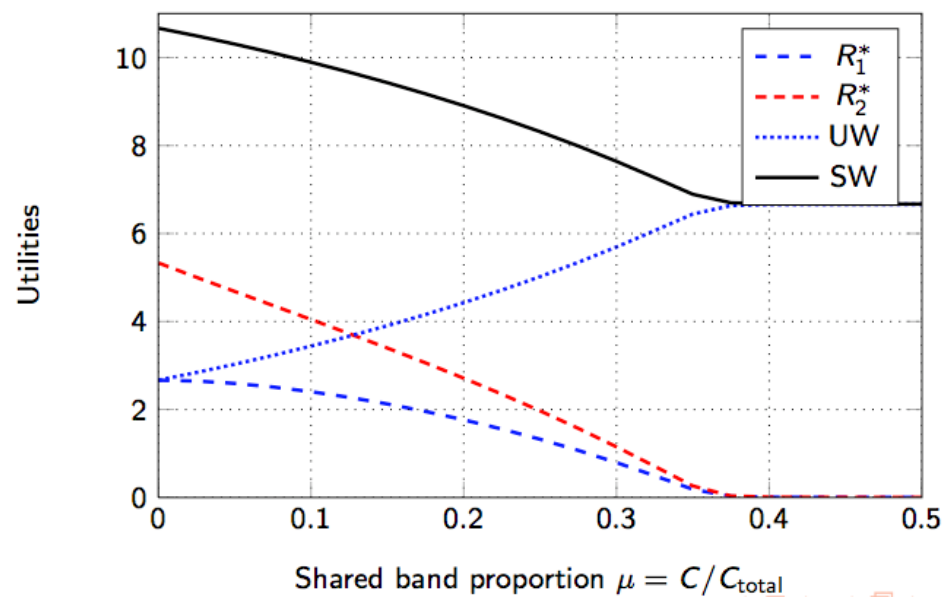

Fig. 6. Utilities in terms of the proportion of shared spectrum 
What can be concluded from Figure 6 is that licenses are beneficial to providers (in our competitive environment) because their revenues decrease with $\mu$, while it is the opposite for user welfare. Social welfare decreases too, but if we put a weight a bit more important on user welfare, an optimal intermediate situation can be obtained.

\section{Other Competition Issues}

Other competition issues can be treated and have been dealt with during Econ@Tel and CAPTURES projects. First, we have discussed in $[5,6]$ competition in the case when customers churn, i.e., switch from one provider to another (this phenomenon has a considerable impact on network provider revenues due to its frequency). To prevent users from switching to another provider, operators can use retention strategies that have to be studied and sanctioned if they keep from an efficient use of the resources. We analyze the price war and regulation procedures (sanctions for providers) leading to the best equilibrium.

But competition is not only at the access provider level, it can be at the content provider level. The typical game is a content and advertising game (mainly how content providers earn money). As an illustration, we have studied in [9] two search engines (which could be Google, Yahoo! or Bing) in competition for advertisers (search engines usually displaying advertising slots when a search is performed), those advertisers having a fixed budget to split among search engines. The revenues of all actors depend on the market share of engines, their ranking and pricing rules, and the profile of strategies of advertisers. Here too, a two level game can be constructed with at the largest time scale the search engines choosing their ranking and pricing strategy, and at the lowest time scale, the advertisers splitting their advertising budget. Again the game is analyzed by backward induction, the engines being assumed to anticipate the reactions of advertisers. This helps to define the best ranking and pricing strategies in a competitive context, something not really studied in the area.

Other important issues are treated in other sections of this book, such as the competition for security, not really dealing with content or broadband/access but rather something transversal, and the network neutrality debate (discussed in a previous chapter), which aims at defining the relations between access providers and content providers, those entities trying to deviate from a cooperative behavior.

Open Access. This article is distributed under the terms of the Creative Commons Attribution Noncommercial License which permits any noncommercial use, distribution, and reproduction in any medium, provided the original author(s) and source are credited.

\section{References}

1. Courcoubetis, C., Weber, R.: Pricing Communication Networks|Economics, Technology and Modeling. Wiley (2003)

2. DaSilva, L.: Pricing of QoS-Enabled Networks: A Survey. IEEE Communications Surveys $\&$ Tutorials 3(2) (2000) 
3. Greene, W.: Econometric Analysis. Prentice Hall, London (1997)

4. Koutsoupias, E., Papadimitriou, C.: Worst-Case Equilibria. In: Meinel, C., Tison, S. (eds.) STACS 1999. LNCS, vol. 1563, pp. 404-413. Springer, Heidelberg (1999)

5. Maillé, P., Naldi, M., Tuffin, B.: Competition for migrating customers: a game-theoretic analysis in a regulated regime. IEEE Globecom (December 2008)

6. Maillé, P., Naldi, M., Tuffin, B.: Price war with migrating customers. In: 17th Annual Meeting of the IEEE/ACM International Symposium on Modeling, Analysis and Simulation of Computer and Telecommunication Systems (MASCOTS 2009). IEEE Computer Society (September 2009)

7. Maillé, P., Tuffin, B.: Price war with partial spectrum sharing for competitive wireless service providers. IEEE Globecom (December 2009)

8. Maillé, P., Tuffin, B.: Price war in heterogeneous wireless networks. Computer Neworks 54(13), 2281-2292 (2010)

9. Maillé, P., Tuffin, B.: Sponsored search engines in competition: Advertisers behavior and engines optimal ranking strategies. In: 19th Annual Meeting of the IEEE/ACM International Symposium on Modeling, Analysis and Simulation of Computer and Telecommunication Systems (MASCOTS 2011). IEEE Computer Society (July 2011)

10. Maillé, P., Tuffin, B.: Competition among providers in loss networks. Annals of Operations Research (2011) (to appear)

11. Maillé, P., Tuffin, B., Vigne, J.: Economics of technological games among telecommunication service providers. IEEE Globecom (December 2010)

12. Maillé, P., Tuffin, B., Vigne, J.: Technological investment games among wire-less telecommunications service providers. International Journal of Network Management 21, 65-82 (2011)

13. Marbach, P., Berry, R.: Downlink resource allocation and pricing for wireless networks. In: Proc. of IEEE INFOCOM (2002)

14. Osborne, M., Rubenstein, A.: A Course on Game Theory. MIT Press (1994)

15. Tuffin, B.: Charging the Internet without bandwidth reservation: an overview and bibliography of mathematical approaches. Journal of Information Science and Engineering 19(5), 765-786 (2003)

16. Wardrop, J.: Some theoretical aspects of road traffic research. Proceedings of the Institute of Civil Engineers 1, 325-378 (1952) 